\section{Preparation has a future!}

\author{
Paul P H Le Brun
}

Fewer and fewer pharmacists are involved with preparation. This has resulted in less attention on this part of the profession in the university curriculum and during the training of hospital pharmacists. However, knowledge of preparation may not be lost. After all, it is a unique activity reserved for the pharmacist.

There is no need to go back to the past when all pharmacists were preparing medicines and had all the technical knowledge-for example, knowing how an autoclave works. It also not necessary to read the Good Manufacturing Practice regulations every day. The point is that all pharmacists must have a knowledge of products. This is necessary to be able to make the right choices when purchasing medicines, when recognising counterfeits, and above all to ensure that medicines can be prepared when they are needed but are not available on the market. This includes the adaptation of a preparation for administration to children or to patients with swallowing difficulties. It is not only about adjusting the dose, but also about knowledge of the formulation in relation to the patient. Take, for example, Acetem-containing oral solutions: insufficiently developed fat digestion in neonates can lead to absorption problems. Without this knowledge, optimal treatment is not possible. Furthermore, personalised medicine is becoming more and more the norm in healthcare and thorough product knowledge is needed. In short, clinical problems can be solved with knowledge of the product.

In addition, there are factors that require a prominent role for preparations in hospital pharmacies:

Department of Clinical Pharmacy and Toxicology, Leiden University Medical Center, Leiden, Netherlands

Correspondence to Dr Paul P H Le Brun, Department of Clinical Pharmacy and Toxicology, Leiden University Medical Center, Leiden, The Netherlands; P.P.H.le_ Brun@lumc.nl
- Temporary shortage of medicines: in various cases, shortages can be solved by stock preparations made in the pharmacy (eg, procainamide injection, magnesium sulphate injection, isoprenaline injection).

- Patient safety: reconstitution of medicines is a high-risk process. We all know examples of injuries due to incorrect reconstitution (eg, a 10-fold dose of phenytoin or a contaminated multi-dose bottle of propofol). This is why there is an increasing need for safe ready-to-use medicines. Some are available on the market, but most need to be prepared in hospital pharmacies.

- Personalised medicines: there are developments where the involvement of pharmacy preparations is required such as advanced drug therapies (ATMPs), tumour imaging with patient-specific peptides and vaccine therapy.

- Medicine costs of orphan drugs are sometimes irresponsibly high. The pharmacy preparation might offer a solution.

\section{LEGISLATION}

Is it also necessary to amend legislation at some point? When it comes to quality, certainly not. When it comes to delivery, it is desirable that the rules are uniformly anchored in Europe. It is to be expected that preparation and analysis will take place more and more in specialised centres. Therefore, delivery between pharmacies will be needed with regard to efficiency, quality and costs. Another consideration is registration. Full-blown registration for pharmacy preparations is not feasible. Therefore, an alternative form of registration is desirable and possible, certainly when we work together in product development and sharing outcome data with regard to efficacy and safety.
KNOWLEDGE AND TRAINING

Is there a future for pharmacy preparation? Certainly! But we must not forget to invest in the knowledge and training of our students and pharmacists. This is why EAHP has invested in a European textbook on product care: Practical Pharmaceutics.

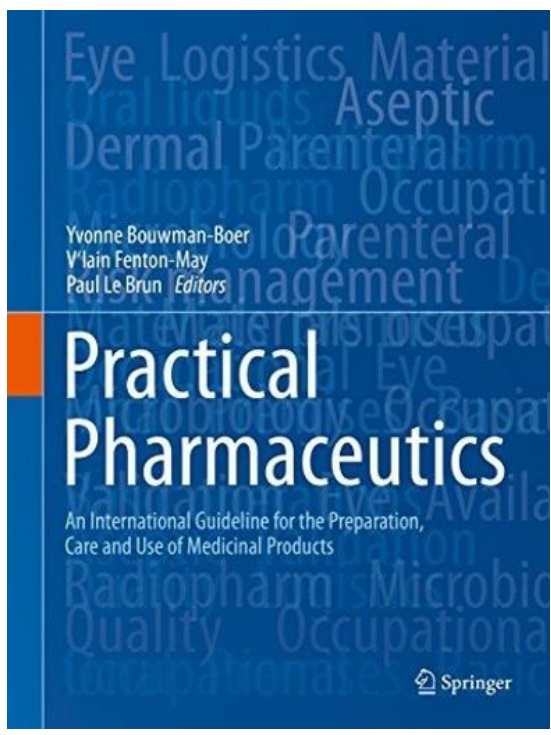

We make an urgent appeal to universities and professional organisations to ensure that the knowledge and skills of preparation and analysis are sufficiently retained for the profession. After all: no patient care without product care.

Funding The author has not declared a specific grant for this research from any funding agency in the public, commercial or not-for-profit sectors.

Competing interests None declared.

Provenance and peer review Not commissioned; internally peer reviewed.

(c) European Association of Hospital Pharmacists 2019. No commercial re-use. See rights and permissions. Published by BMJ.

A Check for updates

To cite Le Brun PPH. Eur J Hosp Pharm 2019;26:300. Published Online First 8 October 2019

Eur J Hosp Pharm 2019;26:300.

doi:10.1136/ejhpharm-2019-002087 